\title{
NOS LUGARES ACOSTUMADOS, O DESEJO: \\ LEITURA SUBJETIVA E ESCRITA DE SI COMO POSSIBILIDADES DE UMA EDUCAÇÃO LITERÁRIA ESTÉTICA E INSUBMISSA ${ }^{1}$
}

\section{IN THE CUSTOMARY PLACES, THE DESIRE: SUBJECTIVE READING AND PERSONAL WRITING AS POSSIBILITIES OF AESTHETIC AND INSUBORDINATE LITERARY EDUCATION}

\author{
https://doi.org/10.20873/uft2179-3948.2020v11n3p103-127
}

Nathalia Cardoso ${ }^{2}$

\begin{abstract}
Resumo
A leitura do texto literário na escola, muitas vezes, remonta a matrizes epistemológicas embasadas em obediência, exclusão e funcionalização de corpos e subjetividades. Diante desse cenário, exploramos neste artigo uma experiência de educação literária realizada numa turma de $8^{\circ}$ ano do Ensino Fundamental de escola federal da Zona Sul do Rio de Janeiro. Para isso, utilizamos os conceitos de leitura subjetiva, de Annie Rouxel, de conversa literária, de Cecília Bajour, e de estética da existência, de Michel Foucault, considerando que o trabalho com o texto literário produz liberdade(s) e (re)existência a determinados exercícios de poder-saber que ainda vigoram na escola.
\end{abstract}

Palavras-chave: educação literária; leitura subjetiva; conversa literária; escrita si; (re)existências

\begin{abstract}
The reading of literary texts at school, more often than not, still traces back to epistemological matrixes that are based on obedience, exclusion, and usage of bodies and subjectivities. In view of this scenario, this article explores a literary experiment carried out in an 8th grade class at a federal school in the south region of Rio de Janeiro. For this purpose, we use the concepts of subjective reading by Annie Rouxel, literary conversation by Cecília Bajour, and aesthetics of existence by Michel Foucault, considering that working with literary texts generates freedom(s) and (re)existence to certain power-knowledge exercises still present in the educational system.
\end{abstract}

Keywords: literary education; subjective reading; literary conversation; self-writing; (re)existences

\footnotetext{
${ }^{1} \mathrm{O}$ presente artigo é decorrente da dissertação de mestrado Experiências de educação literária na Educação Básica - Dos lugares acostumados à produção de desejo: literatura como exercício estético da existência, apresentada ao Programa de Pós-Graduação do Profletras, da Faculdade de Letras da Universidade Federal do Rio de Janeiro, sob orientação da Prof. Dra. Ana Crélia Penha Dias.

2 Professora do Colégio Pedro II, mestra em Letras - Estudos Literários pelo Profletras UFRJ, atualmente, doutoranda em Filosofia na pela UERJ.
} 
A harmonia secreta da desarmonia: quero não o que está feito, mas o que ainda se faz.

Clarice Lispector, Água-Viva

\begin{abstract}
Mas a gente vai começar a ler assim, do nada? E a gente é que vai ler? (...) Professora, o titulo da folha não é estudo do conto? Então, a aula é sobre conto. A senhora não vai começar passando nada no quadro? Não vai escrever, para a gente copiar, o que é o conto, quais são as características dele? Como a gente vai ler sem você explicar nada? ${ }^{3}$
\end{abstract}

Na aula de leitura, a fala do estudante, na epígrafe, nos dá pistas de certo tipo de relação com o literário, não raro construída com ajuda da escola. Desejoso de segurança para a entrada no texto, sua pergunta aponta para um processo, naturalizado, de docilização da experiência estética. O questionamento sobre se as explicações acerca do gênero em foco não viriam antes da leitura, a desconfiança de que sejam os alunos a ler o conto e não a professora, e a ideia de começar a ler assim, do nada nos ajudam a pensar a distância que, tantas vezes, se instaura entre o trabalho realizado com a literatura nas salas de aula da educação básica e o potente universo da experiência e do acontecimento.

Ocorre, entretanto, que as práticas de leitura realizadas na escola não se configuram como um fenômeno isolado; elas repousam sobre matrizes pedagógicas conformadas por quadros ontológicos, epistêmicos e políticos, ou seja, por determinadas relações entre ser, saber e poder. Partindo dessa reflexão, interessa-nos, aqui, realizar dois movimentos principais: o primeiro é o de discutir em que medida certo tipo de trabalho com o texto literário tem contribuído para a manutenção da educação como forma de controle e apaziguamento e para a produção de sujeitos sujeitados (FOUCAULT, 1987) cuja existência, calcada na homogeneização e na produtividade, reforça políticas de exclusão, social e cognitiva; o segundo é o de compartilhar e refletir sobre uma produção que é resultado de uma experiência de educação literária, realizada em uma turma de $8^{\circ}$ ano do Ensino Fundamental, numa escola federal do Rio de Janeiro ${ }^{4}$, cujos eixos centrais são os conceitos de leitura subjetiva, de Annie Rouxel (ROUXEL, 2012), de conversa literária, de Cecília Bajour (BAJOUR, 2012), e de estética da existência, de Michel Foucault (1984), partindo do pressuposto de que o trabalho

\footnotetext{
${ }^{3}$ Fala de um estudante durante uma das aulas de leitura na turma pesquisada, conforme pode ser visto em Cardoso, 2019, p. 52-52.

${ }^{4}$ O Programa de Pós-Graduação do Profletras desenvolve pesquisas relacionadas a experiências realizadas na Educação Básica, em turmas de Ensino Fundamental. Durante o perído de aplicação das práticas pedagógicas propostas na dissertação de mestrado de que decorre este artigo, esta foi a única turma de Ensino Fundamental conferida a mim pela instituição.
} 
com o texto literário, se produz sujeição, é também espaço privilegiado de produção de liberdade(s) e de (re)existência a determinados exercícios de poder-saber que ainda vigoram na instituição escolar.

Dentre os textos que embasaram esse percurso, destacaremos apenas o trabalho realizado a partir do conto Tentação, de Clarice Lispector (LISPECTOR, 1999). É fundamental ressaltar, entretanto, que a metodologia do percurso de leitura sobre a qual falaremos não se configura como uma sequência didática cujo objetivo é o de possibilitar a aplicação em série, como uma fórmula pronta e inequívoca. Isso seria impossível, pois tal concepção de aprendizagem, que deseja estabilizar as práticas pedagógicas para garantir o sucesso sem risco, é avessa à concepção de qualquer trabalho que colha, no respeito à singularidade dos processos, seus resultados.

\section{Leitura literária, poder, sujeição e exclusão}

Grande parte dos centros de ensino ainda é tributária do modelo de educação disciplinar do século XIX e repete a visão mecanicista e funcional presente nas sociedades industriais daquele momento histórico. Esse modelo de educação visa à fabricação de sujeitos úteis e funcionais, tendo como principais ferramentas as análises e avaliações de desempenho, acompanhadas de retificações pertinentes à maximização dos resultados. Nessa engrenagem, em que cada corpo se constitui como peça de uma máquina, confinado pelos espaços esquadrinhados e sob a lógica da produtividade (FOUCAULT, 1987), as relações entre construção de conhecimento e produção de si, entre conhecimento e intersubjetividade, entre aprendizagem e cuidado com o coletivo cedem espaço a uma educação bancária (FREIRE, 2005 [1970]), que transfere conteúdos prontos aos estudantes e, assim, tende a criar relações de passividade em vez de relações de liberdade e autonomia.

Com base nessa perspectiva, muitas escolas de hoje ainda privilegiam o domínio das soluções e não o da formulação de problemas e desconsideram as experiências e o conhecimento prévio dos alunos acerca das questões, tornando-os, muitas vezes, apenas espectadores das aulas. Tais práticas pedagógicas atuam produzindo modos de subjetivação que capturam, modelam, controlam as condutas, as opiniões e os discursos. Nesse sentido, a escola opera um forte movimento de uniformização cultural, desqualificando quaisquer manifestações não hegemônicas (SIBILIA, 2012), desconsiderando a pluralidade e engendrando assujeitamentos (FOUCAULT, 1987). 
Sob os ecos dessas relações entre ser, saber e poder, cujo cerne é a produtividade e o efeito predominante, o da impossibilidade de experiências existenciais significativas, é que muito do trabalho com a literatura tem sido realizado nas escolas. A identificação de figuras de linguagem, descoladas do estudo de seu valor expressivo no texto; a apresentação do literário pautada, sobretudo, na teoria dos gêneros e seguida de listas de características a serem decoradas; aulas em que se estuda, demoradamente, a vida do autor, em vez de o texto; leitura de poesia a serviço da gramática; e testes de verificação de leitura, por exemplo, tudo isso tem contribuído imensamente para a redução da experiência estético-literária a conteúdos programáticos apreendidos pelos estudantes de forma pouco reflexiva e desinteressada

Esse tipo de leitura, analítica, que valoriza, majoritariamente, a decodificação do texto, a assimilação de conteúdos e a verificação dos mesmos não tem sido o único desafio enfrentado pelo estudante em seu percurso de formação como leitor. Outro fator que contribui para o afastamento entre jovens leitores e as obras literárias como lugar de autoconstituição e afetos está no fato de as aulas de Literatura terem se tornado um espaço onde se deve atingir ou aprender uma interpretação consensual do texto, com pouco ou nenhum espaço para a percepção e valorização das reações particulares de coletivos e indivíduos. Segundo Rouxel, trata-se de trabalhar com "um modelo de leitor implícito, no qual o aluno, instituído como leitor, é convidado a desconfiar da leitura ingênua, a se desfazer de condutas espontâneas e subjetivas para respeitar os direitos do texto" (ROUXEL, 2012a, p. 272).

Desse modo, pode-se dizer que a escola, com sua demanda por uma leitura erudita, objetiva e neutra (ROUXEL, 2012a), transforma encontros que poderiam criar aberturas para a implicação do leitor no processo de experimentação do texto em um lugar de desconforto e até de opressão. Assim, grande parte das vezes, os estudantes não veem sentido em fazer as leituras propostas, já que, dentro do processo de ensino de literatura, são, em geral, meros espectadores. De acordo com Rouxel,

[...] a história do ensino de literatura há muito tempo remete a uma exclusão da leitura ou mesmo do leitor como sujeito. [...] Pouco espaço restou para a subjetividade do leitor. [...] A leitura analítica, lenta, que se interessa pelo detalhe do texto, é, muito raramente - exceto para os especialistas -, uma modalidade de leitura para si. Ela é uma prática escolar, espaço de aprendizagem e de avaliação de saberes e competências, dentro do qual, com frequência, "o gesto de ler desaparece sob o ato de aprender"5. (ROUXEL, 2012a, p. 274- 275)

\footnotetext{
5“'O gesto de ler desaparece sob o ato de aprender”. (BARTHES, 1984, p.40-41)
} 
Nesse contexto, está em jogo um silenciamento dos alunos, que se dá através do apagamento de seus saberes e de sua experiência de mundo, na medida em que não há espaço, porque não se deseja que haja, para que o estudante tome a palavra e compartilhe sua leituravida. Tomar a palavra e ler em voz alta, propondo, inclusive, chaves de entrada no texto é fazer uma inscrição no mundo, é inscrever, em ato, a própria existência e, também, criar espaços de escuta de si e do outro, tornando-se sujeito. Negada essa possibilidade, cabe aos estudantes apenas admirar e aprender com a performance do professor, cujas aulas, diversas vezes, partem da teoria - ilustrada pela leitura de fragmentos, na voz desse mesmo professor -, e não do texto. Assim, a experiência estética, singular e intransferível, é domesticada e transformada em conteúdo a ser ministrado.

O ponto final desse percurso, depois da sistemática exclusão da participação ativa do aluno, é a avaliação. Necessário, então, verificar e quantificar o conhecimento que o estudante é capaz de produzir acerca de determinado texto. No ensino fundamental, especificamente, essa é etapa em que o aluno deve demonstrar o domínio das características de determinados gêneros, comprovando suas respostas. Na avaliação, precisa exercer a sua competência leitora, aquela que pouco foi convocada ou construída, de forma coletiva, nos momentos anteriores ao do exame. O problema não consiste em avaliar, mas em como avaliar.

Frequentemente, a escuta das leituras singulares limita-se a atividades pontuais, que não consistem em horizontes de leitura - ou seja, em um ponto de partida enunciado pelos alunos, compartilhado, discutido, encampado ou mesmo questionado diante das possibilidades do texto - isso porque o espaço de compartilhamento de leituras não é uma abertura em que tudo o que é dito será validado, onde impera a opinião dos alunos sobre a materialidade do texto. Trata-se, sim, de criar um espaço de escuta, inclusive, para que aquele aluno cuja leitura permanece superficial ou não cabe no texto possa ter, através da fala dos outros estudantes, sua interpretação tensionada, possibilitando, assim, a construção de outros caminhos.

A voz do professor não deve ser a única a promover questionamento às leituras feitas, tampouco a única a produzir sentidos, pois os estudantes podem, também, posicionar-se interagindo uns com os outros, configurando, assim, uma comunidade de leitura. Além disso, é importante ressaltar que a relevância dada à voz dos alunos em todo esse percurso não apaga em absoluto o papel do professor especialista, fundamental e irrevogável. É ele quem cuida desse espaço de "conversa literária" (BAJOUR, 2012, p. 46) e orienta os estudantes, compondo o panorama de leituras e fazendo as interlocuções necessárias, a partir de seu aporte teórico. 
Portanto, não se está em jogo uma “celebração acrítica da escuta” (BAJOUR, 2012, p. 61), mas sim um diálogo. Ocorre, entretanto, que, pelo fato de muitas aulas caminharem ainda na contramão desse tipo de prática, a leitura tem figurado como um saber externo ao sujeito, e não como uma experiência. Se os estudantes não são convocados a participar ativamente do jogo de construção de sentidos do texto, a exercitar sua atenção - não por meio de exercícios mecânicos e sem sentido, mas daqueles que contribuam para a criação de uma disciplina puramente educativa, que ajudem a criar corpos e mentes atentos -, não há condição para a experiência, condição para que algo os perpasse, os toque, lhes aconteça (LARROSA, 2019).

Ao discutir o problema da lógica de negação da experiência no mundo contemporâneo, Larrosa ressalta o lugar dos aparatos educacionais funcionando cada vez mais no sentido de impossibilitar que a experiência aconteça. Segundo o autor, o sujeito da formação permanente e acelerada usa o tempo como mercadoria e está sempre comprometido com a reciclagem de sua formação, pois não pode ficar para trás, de modo que se torna refém da velocidade do tempo que passa e, paradoxalmente, já não tem tempo. Igualmente, a escola, possui cada vez mais conteúdos a serem ministrados em cada vez menos tempo, mantém professores e alunos trabalhando em ritmo acelerado e nada lhes acontece, segundo a observação de Larrosa. Assim, a educação fica novamente fora da possibilidade existencial, e, como afirma o autor, "tudo o que se passa está organizado para que nada aconteça" (LARROSA, 2001, p. 21).

Larrossa ressalta, ainda, a importância de pensar não só a experiência, mas o sujeito da experiência, que, marcado por uma abertura, uma disponibilidade, expõe-se e, em meio à vulnerabilidade e ao risco implicados nessa exposição, é acontecido. Algo lhe acontece e já está acontecido. Essa exposição ao acontecimento, entretanto, não é algo programado, posto que não é possível impor a si ou a alguém essa receptividade, pois ela se desvela numa passividade da qualidade da paixão, espontânea, como disponibilidade ontológica. No entanto, se não é possível programar a experiência, é possível cuidar do espaço da sala de aula de forma ética, não no sentido moral e normativo, mas enquanto construção de um lugar, uma morada, um território que possibilite as condições para que o sujeito da experiência seja afetado. Para isso, é fundamental que os estudantes façam parte da construção das leituras, que falem sobre suas percepções e sejam ouvidos, engendrando um espaço de presença, aberto ao tempo do acontecimento. É a presença dos alunos e do professor, do texto estudado, do tempo para além do tempo reificado que ajuda a tornar o estudo uma ascese "um exercício de si, no pensamento" (FOUCAULT, 1984, p. 13), que, ao criar corpos e mentes atentos, transforma-os em superfícies sensíveis à experiência. 
A experiência transforma o sujeito, destituído de suas certezas cuidadosamente construídas, e dela emerge um saber que é corpo, que não está apenas na dimensão dos saberes abstratos, conceituais e quantificáveis. Trata-se de um responder ao que nos acontece, atribuindo sentido a esse acontecer. Assim, está intimamente ligada à dimensão da poiésis: habitada pelo humano, ela é singular e intransferível - não se experimenta pelo outro, não se arrisca pelo outro -, tem qualidade existencial. É pela experiência que nos apropriamos de nossa vida, produzimos liberdade e (re)existimos. Então, quando a experiência é impossível, a existência também o é, o que nos convoca a refletir de que educação literária estamos falando.

Nesse sentido, um questionário respondido no primeiro dia de aula pela turma participante do percurso de pesquisa referido neste trabalho contribuiu para pensar sobre a questão da impossibilidade da experiência na escola. A observação de uma das alunas, por exemplo, inspira cuidados com as aulas de leitura. À pergunta "Conseguiria se lembrar de alguma leitura que tenha sido importante para você, que tenha marcado sua vida ou mudado sua forma de ver o mundo? Se sim, diga qual e por quê?", ela responde: “Não. Nunca nenhum livro mudou minha forma de pensar." Evidentemente não pretendemos aqui considerar que essa fala representa a totalidade do trabalho com os textos literários nas escolas; por outro lado, também não é factível supor que esse tipo de vivência seja tão-só uma especificidade dessa aluna.

Outras respostas, dadas por outros estudantes, levam-nos, também, a perceber que muitas vezes as aulas de leitura, no contexto de que fazem parte esses alunos, parecem distantes da concepção de que a obra de arte é uma das mais caras moradas da experiência, território de produção ativa de subjetividades e de modos de existência. A recorrência da reivindicação por mais leitura parece apontar para essa direção. É como se os alunos reclamassem o direito de habitar espaços onde possam ser afetados, em que o corpo se dê a vestígios, marcas e efeitos. Para as perguntas "Você gosta das aulas de leitura?" e "Você teria alguma sugestão para essas aulas?”, aparecem respostas como "Gosto das aulas de leitura, apesar de não ter tido muitas aulas assim.", “Não tenho aula de leitura. Como sugestão: gostaria que elas existissem.", "Como sugestão, gostaria de mais textos e menos questões.".

Essas colocações suscitam alguns questionamentos. Por que esses alunos consideram que não há aulas de leitura ou que são poucas? Como, então, estariam sendo trabalhados os textos lidos durante o percurso pedagógico? Especificamente, em relação à última resposta (“Como sugestão, gostaria de mais textos e menos questões"), estaria o estudante, em alguma medida, sinalizando que as práticas com os textos têm sido baseadas, sobretudo, na resolução 
de questões? Estaria, em última instância, reivindicando seu "direito à literatura" (CANDIDO, 2004, p. 169)?

Tais práticas de trabalho com a literatura desautorizam o aluno a falar sobre os textos. Classificado como bom, regular, mau ou péssimo aluno, muitas vezes apenas com base na nota tirada no exame, o estudante passa, ele mesmo, a desacreditar da relevância de suas leituras e da possibilidade de sua participação na aula ser uma das linhas de construção dos saberes. Hospedeiro do discurso pedagógico, assume o lugar de mero ouvinte de dizeres que não o afetam e vê sentido no próprio silêncio, subordinado a um saber sem corpo, distante da experiência.

Outro problema grave, fruto dessa pedagogia feita para os estudantes e não com eles, é que, privados da relação afetiva com a literatura na escola, os alunos sentem-se cada vez mais distanciados da leitura. Assim, o trabalho com o texto literário geralmente reforça a manutenção de um sistema de privilégio de classe. Não são raros, no contexto da pesquisa, alunos de classe média que vivenciam, em casa, uma cultura literária. Para eles, a escola não é a única possibilidade de contato com o mundo da ficção: suas famílias indicam-lhes obras, levam-nos a feiras de livros, presenteiam-nos com leituras em datas festivas; há estantes de livros em suas casas. Desse modo, a leitura lhes chega conectada à dimensão do afeto e, em alguma medida, faz parte de seu quotidiano.

Por outro lado, sabe-se que em contextos de expropriação e vulnerabilidade o encontro com os livros não se dá com tanta facilidade, mas, muitas vezes, sob a forma de resistência montar bibliotecas que congreguem leitores, garantir tempo de leitura, criar eventos literários, por exemplo, são atos de resistência a políticas que favorecem a desigualdade do acesso à leitura. Para essa parcela da população, muitas vezes, a escola é uma das vias mais importantes ou mesmo a única para a experiência com os livros. Assim, um trabalho relacionado ao texto literário que não possibilita o encontro de afeto e leitura, em alguma medida, contribui para que o capital literário, um dos elementos do capital cultural (BOURDIEU, 1982), mantenha-se majoritariamente como monopólio das classes privilegiadas.

Não se trata de defesa de um discurso determinista, pois sabemos que, inúmeras vezes, a despeito de toda a questão estrutural, os grupos marginalizados seguem apresentando êxito escolar e produzindo grandes intelectuais. Trata-se de tornar (ainda mais) visíveis as desigualdades que ajudam a manter determinado status quo e tensionar o discurso meritocrata tantas vezes presente na escola, o qual faz parecer que todas e todos partem do mesmo lugar e bastam o esforço e a vontade individuais para se alcançar lugares de privilégio. Desse modo, 
pensar novas epistemologias e novas práticas para os caminhos da educação literária é um compromisso político. Ignorar, por outro lado, a necessidade dessa revisão é corroborar com a agenda do Estado colonial brasileiro, cujo projeto foi e tem sido manter marginais determinados corpos e subjetividades e, embora, muitas vezes, o papel dessa lógica de exclusão recaia sobre as ciências exatas, a verdade é que, também, certo tipo de trabalho com a literatura serve a esse propósito, talvez de forma ainda mais perversa: silenciosamente.

\section{Educação literária e (re)existência(s) na escola: leitura subjetiva e estética da existência}

Temos de aprender com os artistas, e em todo resto ser mais sábios do que eles. Pois neles termina normalmente esta sua requintada faculdade: onde a arte acaba, começa a vida; nós, porém, que- remos ser os poetas da nossa vida e, em primeiro lugar, das coisas mais pequenas e comuns.

Friedrich Nietzsche, A gaia ciência

As críticas feitas neste texto à escola e ao trabalho com o texto literário não sugerem uma perda de vínculo ou mesmo uma renúncia, mas se trata de um não criativo, cuja potência de revinculação quer levar à produção de amor e boniteza (FREIRE, 2005 [1970]). Em sua Pedagogia do oprimido, Paulo Freire tematiza a negação qualitativa, ou seja, aquela que possibilita a produção de liberdade, o que significa transcender o ressentimento e transformar o não em sim, mediante o estabelecimento de relações criadoras e de afetos afirmativos. Em outras palavras, significa afirmar a própria dignidade e a dignidade do outro. Assim, a liberdade configura-se não como um atributo, mas como uma conquista coletiva, que não pode ser pensada em detrimento do outro, mas com o outro.

Esse é o sentido da educação que buscamos construir, como uma linha de fuga ao instituído, uma educação como prática estética e artística, em que, repensando o poder de forma dialógica, somos todos coaprendizes e coeducadores, portanto, protagonistas (FREIRE, 2005 [1970]). Nesse sentido, acreditamos que, apesar de tantas vezes reforçar práticas automatizadas e automatizantes, o espaço de leitura do texto literário pode figurar como lugar de elevação do caráter criativo da escola, das subjetividades, da vida. Para isso, porém, é preciso criar outros caminhos, por exemplo, acolhendo a singularidade e a multiplicidade de leituras que há no universo da sala de aula. Sobre essa questão, Langlade defende que

[...] o texto geral não existe fora da multiplicidade dos textos singulares que engendra.

[...] Todo texto singular elaborado por um leitor, quaisquer que sejam suas lacunas e insuficiências relativas, qualquer que seja sua porção de delírio, constitui um estado de texto digno de ser apreciado enquanto produção de leitura literária. (LANGLADE, 2013, p. 34-35) 
Nesses espaços é que se dão as intensidades, a "caça furtiva", em que é possível “apoderar-se secretamente da presa textual” e ser apoderado por ela, o contrário, portanto, do "respeito a um ritual, um protocolo, uma codificação" (LANGLADE, 2013, p. 34), contexto em que a fala do especialista não subtrai ou silencia, mas potencializa a voz do estudante. $\mathrm{O}$ que está em jogo é a escuta da voz dos leitores, uma escuta alimentada pela teoria (BAJOUR, 2012). Nesse sentido, práticas de leitura que possibilitem a atuação dos estudantes são importantes, pois lhes asseguram que suas impressões e experiências podem ajudar a construir entradas no texto, o que é fundamental para o estabelecimento de uma boa relação com a leitura. A valorização não somente da experiência intelectual, mas também da sensível, de suas formas de identificação com a obra, parece um bom caminho. A busca pela verdade do texto, por seu sentido último, aquele a que se deve chegar, pode ceder lugar a um apropriar-se do texto e, na leitura, a algo que faça sentido para o leitor produzir.

O percurso de leitura tematizado neste artigo parte do acolhimento da dimensão subjetiva do leitor nas atividades de leitura, do entendimento do texto literário como dispositivo privilegiado de produção de subjetividades e da problematização do trabalho com a literatura restrito a avaliações que, muitas vezes, negligenciam o signo poético e a potência transformadora da experiência estética, ignorando o tempo do acontecimento. Na tentativa de criar um caminho em que escuta(s), teoria(s) e avaliações constituam um processo com o objetivo de tensionar a relação que objetifica e dociliza corpos, subjetividades e literatura, além das contribuições teóricas já mencionadas, pensar a prática da escrita de si, trazida por Foucault (1984), parece bastante oportuno. Ao analisar a capilaridade do poder e as relações de sujeição que ele produz, o filósofo (FOUCAULT, 1987) destaca, entre outros exercícios de poder, o exercício disciplinar e o poder pastoral ${ }^{6}$. O primeiro visa à fabricação de sujeitos funcionais, ao passo que o segundo, à de sujeitos obedientes, cujas identidades devem estar sob constante suspeição, produzindo sujeição e normatividade. Contudo, em sua genealogia, interessa a Foucault também pensar outras técnicas de si, ou seja, modos de subjetivação que possibilitem ao sujeito resistir aos poderes produtores de sujeição, afirmando, em alguma medida, seu quinhão de liberdade.

As técnicas de si podem, portanto, engendrar sujeição ou (re)existência. Elas constituem um saber específico, que se refere ao modo como cada um governa a própria vida e faz dela a mais bela possível, a ponto de servir de inspiração a si e aos outros, às gerações futuras. Nesse

\footnotetext{
${ }^{6}$ CARDOSO, 2019, p. 32-34.
} 
sentido, Foucault (1984) se volta para o estudo da hermenêutica do sujeito no mundo grecoromano, espaço em que a hermenêutica do si, a chamada arte de si, estava no cuidado de si. A inscrição no templo de Delfos conhece-te a ti mesmo se relaciona, segundo o autor, à prática do cuidado de si mesmo, o que possibilita, dentre outras leituras, entender que conhecer-se a si mesmo é, de certa forma, cuidar de si. Assim, a Filosofia, para além de um conjunto de doutrinas, passa a se referir a uma arte de viver, cuja centralidade transcende o âmbito intelectivo e diz respeito ao modo de vida exercido pelo indivíduo.

Esse indivíduo compreende que seus pensamentos, os conceitos e o exercício filosófico operam transformações existenciais, engendrando novas visões e modos de ser, que não se reduzem à moral, pois não está em questão uma conduta, mas uma maneira de ser (CABRAL, 2018). Assim, pode-se dizer que, na filosofia greco-romana, o cuidar de si é uma técnica de si, ou seja, as "artes da existência" ou "tecnologias de si", como Foucault as chamou, seriam

[...] práticas refletidas e voluntárias através das quais os homens não somente se fixam regras de conduta, como também procuram se transformar, modificar-se em seu ser singular e fazer de sua vida uma obra que seja portadora de certos valores estéticos e responda a critérios de estilo. (FOUCAULT, 1984, p.15)

Essas "tecnologias de si" (FOUCAULT, 1984, p.15) revelam a concepção de uma subjetividade plástica, que não está dada, mas que é produzida pela atuação contínua e consciente do sujeito. Dentro desse universo, a escrita de si revela-se como uma das estratégias que possibilitam a relação estética do sujeito consigo, constituindo-se criativamente. Foucault retorna aos gregos, portanto, não para imitá-los, mas para entender de que maneira, na Antiguidade, as práticas de si e os critérios de uma "estética da existência" (FOUCAULT, 1984, p. 16) problematizam os regimes discursivos e os jogos de verdade através dos quais o ser se constitui historicamente como experiência.

Assim, ao se debruçar sobre modos de subjetivação ativos e criativos, autoconstituidores, o autor buscou possibilidades de produção de outras formas de relação com os saberes e poderes que nos sujeitam. Nesse contexto, segundo Foucault (1984), a centralidade da leitura e da escrita aparece na mundividência grega como lugar privilegiado de produção estilística da existência, posto que se realizavam como fenômenos que transcendiam a ordem comunicativa, servindo à formação contínua do sujeito, cuja existência era colocada em jogo no ato de ler e de escrever. Como peça fundamental desse jogo criativo e artístico é que figura a escrita de si sob as formas de hypomnemata - cadernos de anotações dispersas - ou de cartas. Em ambos os casos, o autor dos escritos coloca a própria existência em jogo, a partir de um elemento fundamental: a saída do texto para o contexto, do texto lido para o contexto vivido. 
Essa transposição é que diz respeito à escrita de si. Nos hypomnemata, esse processo parte de anotações de frases e pensamentos heterogêneos, articulados na vida concreta daquele que escreve, ou seja, articula-se, na experiência concreta da vida, aquilo que, textualmente, é heterogêneo e, muitas vezes, não articulável.

A vida é o lugar da articulação dos textos, e, somente nela, os fragmentos podem ser integrados. No caso das cartas, Foucault (1984 [1992]) mostra que, muitas vezes, a pessoa que escreve, ao dar um conselho ou falar como foi o dia, engendra, para além disso, dois outros movimentos: vê-se por meio da escrita e, por meio dela, reforça certo modo de vida. $\mathrm{O}$ ato de escrever diz respeito, portanto, a um modo de atuar sobre si, na totalidade das experiências. Trata-se, como entende Foucault, da escrita como formação de um corpo, conforme expressa a citação seguinte:

[...] o corpo daquele que, ao transcrever as suas leituras, se apossou delas e fez sua a respectiva verdade. [...] A escrita transforma a coisa vista ou ouvida em forças e em sangue. Ela transforma-se no próprio escritor, que constitui a sua identidade mediante essa recolocação das coisas ditas. (FOUCAULT, 1984, p.133)

Essa arte de viver, que produz uma subjetividade plástica, entendida como obra de arte, parte da leitura, pois não é possível tirar tudo de si próprio, e a escrita dos hypomnemata entra nesse processo como forma de recolher a leitura feita, de nos recolhermos sobre ela, por intermédio da subjetivação no exercício da escrita pessoal. Michèle Petit (PETIT, 2013), a respeito das possíveis formas de apropriação de obras literárias, também fala de uma operação de recorte e cola empreendida pelos leitores, bastante próxima dos hypomnemata. Segundo a autora, os leitores recompõem suas maneiras de ser, redesenhando seus próprios contornos por meio dos fragmentos recolhidos na leitura, processo bastante próximo do que Foucault chama de composição de um "logos fragmentário" (FOUCAULT, 1984, p. 131), um aparelho discursivo ao qual se recorre para a produção da existência, para a elaboração dos movimentos do pensamento.

De acordo com Petit (PETIT, 2013), esses fragmentos não representam necessariamente um vínculo com o sentido do texto original, mas emergem da memória como um texto já transformado em texto do leitor, ou seja, em linhas cujo sentido é produzido na relação do leitor com o texto. Nesse sentido, quem lê produz e é produzido pelo que é lido, forjando assim uma relação de estetização de si a partir da leitura.

Quando leio, minha leitura decompõe o texto, caço furtivamente [...]. Apodero-me de um pedaço, levo-o em meus pensamentos, combino-o com outros fragmentos. Com esses materiais tomados emprestados construo uma morada onde habitar [...] e me esqueço do essencial que li: não faço mais passar pelo texto. [E a leitura é também este esquecimento]. (PETIT, 2013, p.87) 
O exercício da escrita de si é uma forma criativa de se relacionar com o poder que nos sujeita, sobretudo, na escola, com o poder disciplinar. Segundo Deleuze (1992), nessa produção de subjetividade, abrem-se rachaduras, linhas de fuga, que possibilitam dobrar o poder, fazê-lo atuar de outro modo. No vocabulário clássico, esse processo de resistência, que envolve a apropriação de si por de si, cunhando singularidade e engendrando empoderamento, era chamado de enkrateia (FOUCAULT, 1984, p. 60), exercício para o qual leitura e escrita eram imprescindíveis. A eudaimonia, para os gregos, o bom viver, passava por cunhar o que se é a partir das leituras que se faz, criando uma ética, conceito que, neste trabalho, aparece pensado para além das relações com a moral e a norma, pois seu sentido é o de criação de um ethos um modo de ser que fortaleça a si e ao outro -, uma morada onde a vida deve ser cultivada. Os hypomnemata e as correspondências figuravam como espaços para esse cultivo, dado que eram, segundo Foucault, textos práticos.

[...] eles próprios objetos de prática, na medida em que eram feitos para serem lidos, aprendidos, meditados, utilizados [...]. O papel desses textos era o de serem operadores que permitiam os indivíduos interrogar-se sobre sua própria conduta, velar por ela, formá-la e conformar-se, eles próprios, como sujeitos éticos. (FOUCAULT, 1984 , p. 16)

O material presente nos hypomnemata compõe um logos boethikos (FOUCAULT, 1984 , p. 131), ou seja, um equipamento discursivo a que se pode recorrer para constituir uma "armadura da conduta quotidiana" (FOUCAULT, 1984 , p. 16). Não se trata, no entanto, de um diário íntimo, mas de um meio para o estabelecimento de uma relação consigo mesmotão adequada e completa quanto possível. Segundo Sêneca (SÊNECA, 1991), a alma deveria fazer desses cadernos não apenas algo seu, mas ela própria. Essa escrita dispersa tem como foco uma existência unificada, uma formação de si por meio de "logoi dispersos" (FOUCAULT, 1984 , p. 132), em que comparecem diferentes autores, diferentes falas. Para Foucault, a escrita de si é um exercício pessoal prático, por si e para si, uma arte da verdade contrastiva, uma maneira refletida de combinar a autoridade tradicional da coisa já dita como singularidade da verdade que nela se afirma e a particularidade das circunstâncias que determinam seu uso.

\footnotetext{
Não se deve elaborar aquilo que se guarda de um autor, de maneira que este possa ser reconhecido, não se trata de constituir retratos reconhecíveis, mas mortos, é a própria alma que há que construir naquilo que se escreve - assim como um homem traz no rosto a semelhança natural com seus antepassados, assim se escreve a filiação dos pensamentos que ficaram gravados na alma. Pelo jogo das leituras escolhidas e da escrita assimiladora, deve tornar-se possível formar para si próprio uma identidade através da qual se lê uma genealogia espiritual inteira. [...] Num mesmo coração há vozes altas, baixas e medianas, timbres de homem e mulher. Nenhuma voz individual se pode aí distinguir, só o conjunto se impõe ao ouvido. Escrever é, pois, fazer aparecer o próprio rosto junto ao outro. (FOUCAULT, 1984 , p. 134)
} 


\section{Utilizar e interpretar: linhas não disjuntivas e mapas movediços}

Nesta seção, percorreremos o hypomnemata de uma das estudantes da turma pesquisada, evidenciando seus processos de apropriação de leitura, além de destacar como os fragmentos recortados dos textos a acompanharam, reverberando outras atividades realizadas na turma. Nesta experiência, leitura subjetiva e leitura teórica não somente coexistiram como também se complementaram, potencializando-se como linhas não disjuntivas que compõem possibilidades de aproximação e apropriação do texto. A leitura subjetiva, no contexto da escola básica, longe de significar solipsismo ou falta de interpretação, alimenta a abertura para o exercício da interpretação, na medida em que os estudantes se percebem parte do processo de construção dos sentidos e passam a experienciar o texto como um lugar de produção de suas subjetividades, onde suas existências estão em jogo e onde se presentificam, mediante diversas formas artísticas, questões que lhes concernem, por espelhamento ou por contraste. Assim, os textos deixam de ser aquilo pelo que tantas vezes são tomados: mera ilustração da teoria dos gêneros, exemplos do uso de determinada figura de linguagem ou obras de sentido pronto e cerrado, que deve ser passivamente aprendido.

Interessam-nos, então, os movimentos em que tanto a "intenção da obra" e a "intenção do leitor", quanto a "utilização" e a "interpretação" da obra (Umberto Eco 7 apud ROUXEL, 2012b), caminhem juntas, numa dupla captura, em núpcias, como um traçado de devir (DELEUZE, 1998, p. 3), para além da lógica binária e dicotômica que durante muito tempo embasou a análise das práticas de leitura. Também, observar as linhas de fuga criadas pelosestudantes para estabelecer suas entradas no texto, afirmando a pluralidade das lógicas por este permitidas e, por fim, as transversalidades e as diferentes dimensões que se presentificam na relação que se estabelece entre leitor e obra, como num mapa movediço, vivo e qualitativo, em que esses dois regimes de leitura se interpenetram.

Tal postura, pedagógica e epistêmica, não significa dispensar a interpretação ou menosprezá-la, negligenciando a significação, senão universal ao menos consensual do texto, uma vez que isso seria tão autoritário quanto marginalizar aprioristicamente "a significação para si" e "o texto do leitor" (ROUXEL, 2012b, p. 152), o que, majoritariamente, temos feito em sala de aula, fortalecendo o

\footnotetext{
${ }^{7}$ ECO, U. Les limites de l'interprétation. Paris: Éditions Grasset, 1990, p. 39 e 40. 39-40
} 
[...] hábito de uma postura que transforma o comentário em "uma decodificação racionalizante mais ou menos complicada" [PICARD ${ }^{8}, 1986$, p. 96], ou em uma "pequena técnica pedagógica [...] empedernida" [COMPAGNON 9 , 1998, p. 11]. É antes de tudo a exclusão do sujeito leitor que é sublinhada nessas críticas e o fato de que, segundo os termos de Christian Baudelot e sua equipe, a leitura literária representa para a maioria dos alunos "uma prática sem crença". (ROUXEL, 2012b, p. 156)

Trata-se, portanto, de entender que essas duas atividades - a utilização do texto e a interpretação dele - não são incompatíveis; aliás, é desejável que possam caminhar juntas no contexto da educação básica, etapa da escolaridade que não tem como objetivo a formação de especialistas em literatura; além disso, levando em conta a situação do Brasil, o cenário de expropriação pode afastar, cada vez mais, o leitor em potencial da leitura. Muitas vezes, é partindo da significação para si (expressão de Rouxel) que o estudante é mobilizado a entrar no texto, podendo, assim, se lançar na aventura de construir sentidos, convocando, para tanto, seu saber sobre a literatura e arriscando-se na abordagem heurística do texto fundada sobre inferências, própria da interpretação, perfazendo nesse movimento, um arco que vai do mais subjetivo ao mais teórico, indo além da utilização do texto (ROUXEL, 2012b).

$\mathrm{Na}$ busca pelo tão desejado equilíbrio entre os direitos do texto e os direitos do leitor, dar espaço à expressão das subjetividades é um passo fundamental para possibilitar que a leitura se torne, efetivamente, uma experiência estética, um espaço de exercício de si, em que o leitor possa operar, de forma consciente, a constituição da própria subjetividade, não pela afirmação de si mesmo, mas pela possibilidade de ser além do que é. Também, é passo fundamental, no contexto da educação básica, para contribuir com que o acesso à leitura se torne efetivamente mais democrático, já que, como destaca Rouxel, interpretar pressupõe convocar um saber sobre a literatura, mobilizando uma "experiência rica e diversa [uma vasta enciclopédia, uma ampla biblioteca interior]", realizar uma "abordagem heurística fundada sobre inferências", pressupondo um modo de pensar racional (ROUXEL, 2012b, p. 153).

Nesse sentido pode-se dizer que interpretar um texto é um privilégio de classe, tendo em vista que acumular um saber sobre literatura, ter uma vasta enciclopédia, uma biblioteca interior e realizar uma abordagem heurística do texto, fundada sobre inferências, configura uma realidade que se manifesta como fruto de uma formação intelectual e emocional a longo prazo, com educação de qualidade e, também, com tempo de dedicação ao estudo garantido e proximidade de ambientes em que haja uma cultura literária - tudo isso se traduz em uma

\footnotetext{
${ }^{8}$ PICARD, M. Lá lecture comme jeu. Paris: Les Éditions de Minuit, 1986, p. 96.

${ }^{9}$ COMPAGNON, A. Le démon de la théorie. Paris: Seuil, 1998, p.11.
} 
estrutura a que, em geral, quem tem acesso são as classes privilegiadas, a elite do país. Outro ponto importante a ser destacado sobre a questão da interpretação é que as bases que norteiam o que se entende por interpretação e o modo como ela deve se dar para que seja legítima, para que se respeitem os direitos do texto, é fruto de uma epistemologia de matriz europeia que, não por acaso, coloca a racionalidade, a pretensa neutralidade como elemento central de sua prática, "a postura crítica e distanciada, característica da cultura letrada" (ROUXEL, 2012b, p. 153).

Assim, parece importante não perder de vista que essa concepção do que seja interpretação atualiza determinadas relações de poder-saber, o que não quer dizer nem que sua legitimidade deva ser questionada nem que essa forma de se apropriar do texto literário tenha que se manter absoluta, em detrimento de todas as outras possibilidades, mas sim que, talvez, "dar sentido à atividade de leitura mediante uma didática da implicação" (ROUXEL, 2012b, p. 157) seja um grande passo em direção a uma educação literária menos colonizada e mais democrática.

\section{O hypomnemata}
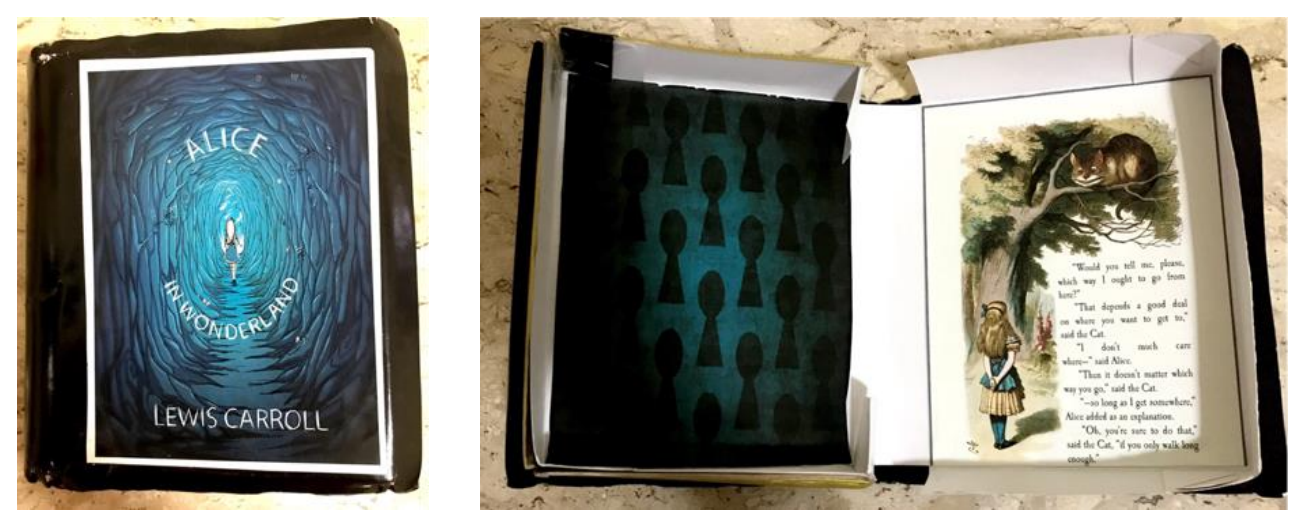

A capa do caderno dessa aluna foi sendo confeccionada aos poucos e, no dia da entrega, estava finalmente concluída: “Ah! Finalmente, acabei, professora! Me deu um trabalhão, eu tive que pensar muito pra fazer isso e ainda pedi ajuda para minha irmã mais velha, que faz Direito". Quando entrei na sala, a menina me chamou e quis me entregar o caderno em mãos. A própria capa do hypomnemata já é fruto de fragmentos roubados de Alice no país das maravilhas (CARROLL, 1998 [1865]), história da menina que realiza sua catábase descendo ao mundo subterrâneo e voltando do mundo originário ao mundo originado já transformada em outra. A primeira imagem do caderno mostra a personagem de Lewis Carroll entrando no buraco da árvore, deixando o mundo conhecido, rumo a uma realidade que ainda é mistério. $\mathrm{Na}$ aula seguinte, perguntei à aluna sobre o significado dessa imagem (e se poderia mostrar o caderno a todos) e ela me respondeu que, assim como Alice entrava em outro mundo pelo 
buraco na cerca viva, ela mesma e o leitor de seu caderno, também, entrariam em outro mundo, o mundo dos textos.

Durante as aulas, foi apresentada a questão das chaves de leitura propostas por eles, a partir dos recortes selecionados. Disse à turma sobre cada obra trazer consigo mesma sua própria chave de interpretação e que o que eles estavam fazendo era construir, a partir das suas leituras da obra, da seleção dos fragmentos e dos comentários sobre eles, chaves de interpretação dos textos. Chaves que às vezes abririam e às vezes não, sendo preciso, portanto, testá-las. Dentro da capa do caderno, à esquerda, há uma série de fechaduras: tendo entrado no buraco, agora o leitor se depara com fechaduras. Mostrando o caderno à turma, perguntei "onde estão as chaves?", e a dona do caderno responde: "No leitor. Por isso, são várias chaves, porque são vários leitores". Um aluno cujo caderno ficou em branco comentou: "Pode crer."10

À direita, já tendo entrado no mundo do originário pela toca do coelho, Alice depara-se com o gato e pergunta sobre qual caminho tomar. Eu pedi que a aluna explicasse à turma porque havia escolhido a passagem do gato. Ela observou que o animal falava sobre a existência de diversos caminhos e que, pelo que havia entendido, os fragmentos eram esses caminhos, que poderiam levar os leitores a diferentes textos. Assim, mais do que ilustrar o hypomnemata com a história de Alice, a aluna criou uma narratividade relacionada ao próprio sentido do caderno: um lugar onde habitar, um lugar onde construir para si uma morada. Assim como a personagem Alice, a autora do caderno, já a partir da capa, convida-nos a entrar em um reino novo, reino que, no hypomnemata, é o da leitura e da escrita, cuja chave é fabricada por cada um que queira entrar. Mais do que ilustrar o caderno com a história de Alice, a aluna propõe uma narrativa que é um convite a penetrar esse mundo desconhecido.

Além disso, a escolha da personagem Alice parece-nos bastante interessante, pois é possível estabelecer alguns pontos de contato com o conto lispectoriano ${ }^{11}$, de onde os primeiros fragmentos foram retirados. Em primeiro lugar, em ambos os textos, estamos diante de personagens femininas que, em alguma medida, vivem o drama da incomunicabilidade: no conto, a menina que suporta sua infância impossível; na história de Alice, já na primeira cena do texto, a protagonista aparece cansada "de ficar sentada ao lado da irmã à beira do lago, sem ter nada para fazer" (CARROLL, 1998 [1865], p. 11).

\footnotetext{
${ }^{10}$ A turma se engajou bastante na leitura do hypomnemata da aluna. Durante os encontros seguintes, outros estudantes também apresentaram seus recortes, que foram discutidos.

11 Tentação. In: Todos os contos/Clarice Lispector. Rio de Janeiro: Rocco, 2016.
} 
O tema da identidade também está presente nas duas narrativas - a criança vermelha do conto de Lispector (LISPECTOR, 1999) se confronta com sua marca insolente, que a identifica como fora da norma: ela era ruiva. Como afirmar e ao mesmo tempo transcender essa identidade símbolo da diferença? É no ângulo quente da esquina que surge o basset ruivo e, nele, o encontro e a acolhida da identidade da menina que deixa de ser outro e encontra sua identidade no cão, tornando-se outra de si mesma. Alice, em sua chegada ao estranho mundo das maravilhas, rapidamente se questiona: "Quem é que eu sou? Ah, essa é a grande charada!" (CARROLL, 1998 [1865], p. 26; e, assim como o cão de Tentação ajuda a menina a afirmar e a transcender a própria identidade, a lagarta e o gato - recortado no fragmento da aluna - fazem essa questão reverberar, como no seguinte diálogo entre a menina e a lagarta, por exemplo:

"Quem é você?", disse a lagarta. Ao que Alice responde: "Eu... eu... no momento não
sei, minha senhora, pelo menos sei quem eu era quando me levantei hoje de manhã,
mas acho que devo ter mudado várias vezes desde então". "O que você quer dizer?
Explique-se!" "Acho que infelizmente não posso me explicar, minha senhora, porque
já não sou $e u$, entende?" (CARROLL, 1998 [1865], p. 61)

Assim, em ambos os textos, a presença de animais, a presença do inumano conduz as personagens a um encontro consigo mesmas, em que se reconfiguram suas existências. $\mathrm{O}$ vermelho, símbolo do sofrimento da personagem no conto de Lispector conforme apontado pelos estudantes em nossa conversa literária, e indiciado na presença do basset, torna-se, também, representação do amor. E, na história de Alice, por meio da presença do Gato de Cheshire, a menina encontra um interlocutor que lhe faz repensar o sentido do que significa a escolha de um caminho.

Dessa forma, não somente não parece ingênua nem gratuita a composição desse hypomnemata, como a leitura do texto Tentação reverbera nela. Foi a partir da compreensão deste texto de Lispector, construída pela leitura individual, pelo recorte dos fragmentos, pela leitura coletiva e pela teoria que dela emergiu que a aluna pôde convocar Alice para fazer parte da (sua) história. Assim como as personagens se transformam pela potência do encontro com o outro, parece ser esse o convite feito pela aluna a si mesma e ao leitor do caderno: encontrarse nos fragmentos, nesse outro que é o texto literário, nessas possibilidades de leitura que são um basset ruivo.

Há ainda o desenho dentro da caixa onde a aluna guardava o caderno. Ela me disse: " $A$ ideia é que isso é um livro, entendeu? Não é um caderno qualquer, só que um livro meu, só de fragmentos." Eu perguntei por que a estatueta do Oscar e ela me respondeu que era uma disputa 
entre os melhores fragmentos e que eles mereciam ser premiados. Premiados com uma estatueta em que está escrito "País das Maravilhas". Os fragmentos levam ao País das Maravilhas?

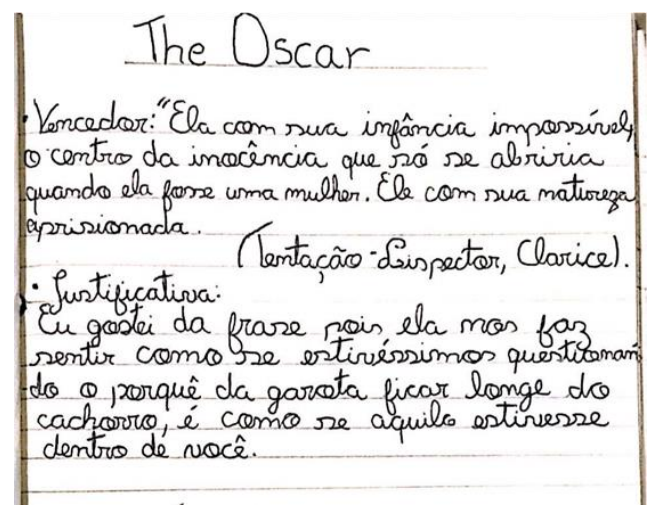

Quanto aos recortes, a respeito de um dos trechos que escolheu do conto de Lispector, aliado ao comentário sobre ele, a aluna demonstra a percepção de que a narrativa possibilita a identificação do leitor com a personagem; leitor que, empaticamente, passa a sentir a iminência de afastamento do cão. Ao destacar que "é como se aquilo estivesse dentro de você", a aluna se aproxima do texto a partir de sua subjetividade, mas seu é como se revela certa compreensão da construção do jogo ficcional. Ela não é a personagem, mas, no momento da leitura, esses eus se misturam e é como se aquilo estivesse dentro. Esse dentro já não é mais o mesmo, transfigurado, por um devir-ruiva, por um devir-animal.

Ao elencar esse fragmento, a aluna toma posse dessa experiência, (re)qualifica-a a partir da articulação do trecho, que é uma síntese daquilo que mais a toca, que mais toca à sua própria vida. Esse caderno não é um diário íntimo, e, sim, como nos ensina Foucault, um "logos fragmentário" (FOUCAULT, 1984 p. 131), um aparelho discursivo ao qual se recorre para a produção da existência, para elaboração dos movimentos do pensamento, recompondo os próprios modos de existência, resdesenhando os próprios contornos, por meio dos fragmentos recolhidos na leitura. Assim é a escrita de si através dos hypomnemata: é um tomar posse das leituras, "fazendo delas sua respectiva verdade"; é, através da escrita, transformar o lido "em forças e em sangue"; é constituir a própria identidade mediante a recolocação desses fragmentos (FOUCAULT, 1984 , p. 5).

O caderno mostrado, um dos exemplos de nosso percurso, permite observar como a prática da "leitura subjetiva" (ROUXEL, 2012a, p. 276), da "conversa literária" (BAJOUR, 2012, p. 46) e da "escrita de si" (FOUCAULT, 1984 , p. 1) possibilitam a construção da autonomia de alunas e alunos como leitores e favorecem a emersão de relações de autocuidado 
e de constituição consciente de si, mediante a leitura e a escrita, configurando, portanto, um exercício ético, estético e político. Através da leitura dos hypomnemata é possível acompanhar as formas de apropriação dos textos realizadas pelos alunos, bem como o processo por meio do qual eles ganham confiança, tornando-se partícipes da construção das aulas, das reflexões sobre o texto, saindo da posição de passividade de quem apenas recebe informações sobre algo e assumindo a postura de sujeito.

Tomando a palavra, lendo os fragmentos que haviam selecionado, comentando o texto, discordando da interpretação ou do "discurso sobre si" (ROUXEL, 2012b, p. 160) das companheiras ou companheiros de turma, os estudantes se inscrevem no mundo. Observando os seus percursos de leitura, é possível perceber como a relação com os textos literários, em grande parte dos casos, começa a transcender a funcionalização - a leitura da obra como meio para atingir determinado fim: fazer o teste, passar na prova, no vestibular. Claro é que a conquista de um lugar no mercado de trabalho é essencial para todas e todos: nossos alunos têm direito a isso, e é nosso dever, como educadores, nos engajarmos nessa tarefa. Afinal, em um país como o Brasil, cujo fosso social é imenso, o estudo ainda se revela como principal meio de mobilidade social, ainda que, muitas vezes, a escola instale o que Orlandi, lendo Bourdieu, chama de "circularidade" (ORLANDI, 2003, p. 22): a correspondência entre a distribuição do capital cultural e do capital econômico e do poder entre as diferentes classes.

Portanto, não se trata de uma despreocupação com uma formação sólida, que possibilite aos estudantes ocupar seus lugares de direito, mas de como criar espaços onde o estudante possa praticar a sua ascese, seu "exercício de si no pensamento" (FOUCAULT, 1984, p. 13), possibilitando, tanto quanto possível, que o estudo faça sentido e que seja um lugar do pensamento, de uma leitura que, como afirma Larrosa em seu “Abecedário" (2019), se coloque como

uma maneira de ler a que se pode chamar pensativa, uma maneira de ler que está escondida ou ritmada por essa estranha interrupção a que chamamos de pensamento, por essa coisa rara que é parar para pensar. [...] E onde estamos quando pensamos? Em nenhuma parte. E há pessoas que amam essa "nenhuma parte" como se ela fosse um país. Os que pensam são habitantes desse país. (LARROSA, 2019)

As práticas de leitura pautadas em uma concepção "dialógica da escuta” (BAJOUR, 2012, p. 25), que valorizam o momento em que o leitor levanta a cabeça, que garantem o lugar dos estudantes como parte fundamental da construção de sentidos do texto lido, produzem desejo, possibilitam a visita ao "nenhum local" de que fala Larrosa. Tais práticas contribuem também para a difícil tarefa de tensionar a idealização do professor como doador de sentidos das obras e reservam aos alunos o direito à voz, à escola como espaço de acesso democrático à 
leitura, à literatura. Ao longo das análises da produção dos estudantes, foi possível observar como a primeira etapa do trabalho com a "escrita de si" (FOUCAULT, 1984, p. 129), a partir do recorte dos fragmentos lidos e discutidos em sala, contribuiu para o envolvimento dos estudantes nas aulas de leitura, como se eles carregassem consigo algo que haviam preparado, guardado, como se houvesse um segredo a ser revelado à turma. Contribuiu, portanto, para que criassem uma relação afetiva tanto com o momento da aula de leitura quanto com o texto - não necessariamente no sentido de gostar do texto, mas de ser atravessado por ele.

Além disso, ficou evidente como, ao retirar os fragmentos, comentá-los e usá-los na sala de aula ou nas outras produções, os alunos tinham compreendido de que contexto de sentido mais amplo eles faziam parte, ainda que, depois, em outras produções, não só reafirmassem, como recriassem esse sentido. Em um questionário aplicado ao fim da pesquisa, uma aluna comentou sobre os fragmentos: "Recortar os textos me ajudou a lembrar melhor de partes das obras e do porquê eu gostei dos textos. E é interessante... porque é como se fosse um livro que eu mesma fiz, carregado de emoções. Os trechos selecionados são muito importantes para mim." Outra aluna afirma: "Acho que para conseguirmos tirar os fragmentos dos livros, precisamos ler com muita atenção para saber o contexto. Os trechos escolhidos, significam muito para mim pois são partes da minha vida."

Os fragmentos dos hypomnemata compõem um corpo, um corpo daquele que, "ao transcrever suas leituras, se apossou delas e fez sua respectiva verdade: a escrita transforma a coisa vista ou ouvida em forças e em sangue. Ela transforma-se no próprio escritor, num princípio de ação racional" (FOUCAULT, 1984 , p. 5). Esse é o processo de subjetivação a partir da leitura e da escrita que a aluna vivencia e sobre o qual ela fala. Os fragmentos recolhidos emergem como chaves de entrada para o texto, síntese da leitura e símbolo de uma experiência acontecida. Assim, está em jogo a possibilidade de um trabalho com o texto literário que mobiliza afetos e exercita o pensamento, ajudando na constituição de uma "sensibilidade inteligente". Um tipo de sensibilidade que "não só se comove como por assim dizer pensa sem ser com a cabeça” (LISPECTOR, 1999, p.162).

Esse trabalho evidencia, também, a importância de que as matrizes epistemológicas que orientam o trabalho com o tex to literário sejam constantemente repensadas, e não tratadas como dados absolutos. Não basta pensar novas práticas de leitura, novas sequências didáticas, novas metodologias. Não basta revisar o cânone, embora essa ação configure um movimento essencial, importantíssimo e urgente em direção à justiça e aos incontáveis ganhos que isso significa para todas e todos. É preciso dar um passo para trás e pensar tanto em que relações de 
saber-po*der conformam nossas práticas de estudo do texto, nossas práticas de leitura e aulas, como também que tipo de produção de subjetividade está em jogo, ou seja, pensar essas práticas a partir das dimensões ontológica, epistêmica e política. Se não há nem discursos nem conhecimento neutros, pois "só é possível falar de um tempo e lugar específicos, de uma história e uma realidade específicas" (KILOMBA, 2019 [2008], p. 58), será sempre importante perguntar de quem é essa verdade, a quem serve essa verdade. "Quem está no centro e quem permanece fora, nas margens?" (KILOMBA, 2019 [2008], p. 50).

Uma estudante, ao ser perguntada sobre as escolhas de leitura do trimestre, responde: "Achei muito interessantes pois abordam temas que nunca tínhamos estudado na escola". A fala da aluna aponta para problemas explícitos como a questão da representatividade, da manutenção de um cânone masculino e branco, do silenciamento da voz dos grupos subalternizados. Mas há ainda outra pergunta, talvez menos explícita: ela realmente não teria tido contato com obras cujos temas fossem a violência física e simbólica contra as mulheres, o machismo, a invisibilização de determinados grupos, ou, talvez, certo trabalho de leitura não tenha possibilitado que ela fosse atravessada por essas questões?

A escolha dos textos é de suma importância; é, como já mencionamos neste trabalho, lendo Bajour, "a antessala da escuta" (BAJOUR, 2012, p. 52), mas ela não prescinde da escuta. Não prescinde de um trabalho com o texto que repense suas matrizes epistêmicas. Não há nenhuma dúvida de que o texto de Chimamanda Adichie ${ }^{12}$, uma das autoras lidas pela turma, representa uma revolução ficcional. Contudo, é preciso lembrar que houve um trabalho denso, um processo de envolvimento com o texto, um debruçar-se, uma escuta. Será que o envolvimento teria sido o mesmo se a aula tivesse como ponto de partida uma lista de características do gênero conto, ou mesmo das características da obra da autora, em um gesto racionalizante da experiência, que regula o acontecimento?

\section{Considerações finais}

A partir da análise apresentada, este artigo buscou propor alguns caminhos para pensar as práticas de leitura na educação básica. Para pensar, e não para que o movimento singular da experiência estética seja, a partir de explicações totalizantes, enquadrado e transformado numa fórmula a ser repetida. $\mathrm{O}$ devir artístico instaurado pelas obras literárias, que atualiza a potência do diferente, daquilo que possibilita ser outra/outro, pode e deve contar com a abertura de uma

12 ADICHIE, Chimamanda Ngozi. No seu pescoço. São Paulo: Companhia das Letras, 2017/2009. 
pedagogia que mergulhe nos impasses e nos dilemas, que não procure saídas, mas que opere nas tensões, uma pedagogia sensível ao fato de que é um princípio à própria vida que permite julgá-la, e não modelos prontos e reproduzíveis sem erro. Assim, o caminho é construído na singularidade do caminhar. Por isso, cada uma e cada um, na lida diária com suas alunas e seus alunos e consigo mesmo, é que pode, mapeando, a cada vez, os movimentos dos encontros, compreender que ações ou que silêncios hão de possibilitar a potencialização dos afetos produzidos durante o percurso em sala de aula.

Desse modo, consideramos como ponto central desta prática a abertura para a imprevisibilidade, para a consciência de um fazer permanente, inventado com os estudantes, e não para os estudantes. Abertura que se torna possível mediante o exercício constante da atenção e do estudo, da preparação cuidadosa das aulas, da escolha criteriosa das obras. Paralelamente a tudo isso, essa abertura também requer um constante exercício de escuta ativa dos alunos e de seus movimentos, exige uma entrega ao acontecimento e à criação de critérios de trabalho imanentes à ação, recolocando os problemas a cada vez. Trata-se de um exercício de liberdade que acolhe e (trans)forma o que acontece.

\section{Referências}

BAJOUR, Cecília. Ouvir nas entrelinhas: o valor da escuta nas práticas de leitura. São Paulo: Editora Pulo do Gato, 2012.

BARTHES, Roland. Sur la lecture. In: Le Bruissement de la langue. Paris: Seuil, 1984. p. 3747. (Coll. Points-Essais, 4)

BOURDIEU, P.; PASSERON, J.-C. A reprodução: Elementos para uma teoria do sistema de ensino. Rio de Janeiro: Francisco Alves, 1982.

CABRAL, Alexandre Marques. Psicologia pós-identitária: da resistência à crítica das matrizes cristãs da psicologia clínica moderna. Rio de Janeiro: Via Verita, 2018.

CANDIDO, Antonio. O direito à literatura. Rio de Janeiro; São Paulo: Ouro sobre Azul; Duas Cidades, 2004.

CARDOSO, Nathalia. Experiências de educação literária na Educação Básica - Dos lugares acostumados à produção de desejo: literatura como exercício estético da existência. Dissertação apresentada ao Programa de Pós-Graduação do Profletras, da Faculdade de Letras da Universidade Federal do Rio de Janeiro, 2019.

CARROLL, Lewis. Alice no país das maravilhas. Porto Alegre: L\&PM, 1998/1865.

DELEUZE, Gilles. Conversações. Rio de Janeiro: Editora 34, 1992. 
FOUCAULT, Michel. História da sexualidade, v. 2: o uso dos prazeres. Rio de Janeiro: Graal, 1984.

FOUCAULT, Michel. Vigiar e punir: nascimento da prisão. Tradução de Lígia Vassalo. Petrópolis: Vozes, 1987/1975.

FOUCAULT, Michel. A escrita de si. In: FOUCAULT, Michel. O que é um autor? Lisboa: Passagens, 1992. p. 129-160.

FREIRE, Paulo. Pedagogia do oprimido. Rio de Janeiro: Paz e Terra, 2005/1970.

KILOMBA, Grada. Memórias da plantação: episódios de racismo cotidiano. Rio de Janeiro: Cobogó, 2019/2008.

LANGLADE, Gérard. O sujeito leitor, autor da singularidade da obra. In: ROUXEL, Annie; LANGLADE, Gérard; REZENDE, Neide (Orgs.). Leitura subjetiva e ensino de literatura. São Paulo: Alameda, 2012. p. 25-38.

LARROSA, Jorge Bondía. Notas sobre a experiência e o saber de experiência. Conferência proferida no I Seminário Internacional de Educação de Campinas, traduzida e publicada em Julho de 2001, por Leituras SME. Disponível em: http://www.scielo.br/pdf/rbedu/n19/n19a02.pdf. Acesso em: 01.09.2019.

LARROSA, Jorge Bondía. Abecedário de educação, 2016. Canal Youtube. Vídeo, 60'10”. Disponível em: https://www.youtube.com/watch?v=5FtY1psRoS4. Acesso em 01 set. 2019.

LISPECTOR, Clarice. Tentação. In: Todos os contos/Clarice Lispector. Rio de Janeiro: Rocco, 2016, p. 315-316.

LISPECTOR, Clarice. Água-Viva. Rio de Janeiro: Artenova, 1999.

NIETZSCHE, Friedrich. A gaia ciência. Tradução de Paulo César de Souza São Paulo: Martin Claret, 2003/1882.

ORLANDI, Eni Puccineli. A linguagem e seu funcionamento: as formas do discurso. Campinas: Pontes, 2003.

PETIT, Michèle. Leituras: do espaço íntimo ao espaço público. São Paulo: Editora 34, 2013.

ROUXEL, Annie. Práticas de leitura: quais rumos para favorecer a expressão do sujeito leitor?. Tradução de Neide Rezende e Gabriela de Oliveira. Cadernos de Pesquisa, v. 42, n. 145, p. 272-283, jan./abr., 2012a.

ROUXEL, Annie. Mutações epistemológicas e o ensino da literatura: o advento do sujeito leitor. Tradução de Samira Murad. Revista Criação \& Crítica, n. 9, p. 13-24, nov., 2012. Disponível em: http://www.revistas.usp.br/criacaoecritica. Acesso em: 10.10.2019. 
ROUXEL, Annie. A tensão entre utilizar e interpretar na recepção de obras literárias em sala de aula: reflexão sobre uma inversão de valores ao longo da escolaridade. In: ROUXEL, Annie; LANGLADE, Gérard; REZENDE, Neide (Orgs.). Leitura subjetiva e ensino de literatura. São Paulo: Alameda, 2012b. p.151-164

ROUXEL, Annie. Autobiografia de leitor e identidade literária. In: ROUXEL, Annie; LANGLADE, Gérard; REZENDE, Neide (Orgs.). Leitura subjetiva e ensino de literatura. São Paulo: Alameda, 2012c. p.67-87

SÊNECA, Lúcio Aneu. (1991) Cartas a Lucílio. Trad., pref. e notas de J. A. Segurado e Campos. Lisboa: Fundação Calouste Gulbenkian.

SIBILIA, Paula. Redes ou paredes: a escola em tempos de dispersão. Tradução de Vera Ribeiro. Rio de Janeiro: Contraponto, 2012.

Recebido em 29 de julho de 2020. Aceito em 25 de novembro de 2020. 